\title{
Evaluation of Selected Essential Oils as Biocontrol Agents Against Listeria monocytogenes
}

\author{
Chinta Siva Swetha ${ }^{1}$, Porteen Kannan ${ }^{1 "}$, Elango A. ${ }^{2}$, Ronald B.S.M. ${ }^{3}$, Senthil Kumar T.M.A. ${ }^{4}$ and \\ Sureshkannan Sundaram ${ }^{1}$ \\ ${ }^{1}$ Department of Veterinary Public Health and Epidemiology, Madras Veterinary College, Chennai, TN, INDIA \\ ${ }^{2}$ Dean i/c, Veterinary College and Research Institute, Salem, Tamil Nadu, INDIA \\ ${ }^{3}$ Department of Veterinary Microbiology, Madras Veterinary College, Chennai, Tamil Nadu, INDIA \\ ${ }^{4}$ Central University Laboratory, CAHS, TANUVAS, Madhavaram Milk Colony, Chennai, Tamil Nadu, INDIA
}

*Corresponding author: P Kannan; E-mail: rajavet2002@gmail.com

Received: 01 Aug., 2020

Revised: 18 Sept., 2020

Accepted: 29 Sept., 2020

\begin{abstract}
The increased concern towards food safety led to application of natural extracts as antimicrobial agents to control food borne pathogens. The aim of the present study was to determine antimicrobial activity of the four essential oils viz., cinnamon bark, cinnamon leaf, clove bud and garlic oils against Listeria monocytogenes by agar well diffusion method. All these essential oils were characterized by Gas chromatography-mass spectrophotometer (GC-MS) to know the chemical constituents present in them. Out of these four oils, L. monocytogenes was found to be sensitive to cinnamon bark oil, followed by cinnamon leaf oil, clove bud oil and garlic oil. Further, all these oils were evaluated to know minimal inhibitory concentration (MIC) and the cinnamon bark oil alone was found to be effective with a MIC of $1 \%$ against L. monocytogenes. The present study findings suggest that plant based natural extracts might be used as antimicrobial, flavouring and food biopreservative agent.
\end{abstract}

\section{HIGHLIGHTS}

(0 Cinnamon bark oil at $2 \%$ and $1 \%$ showed minimum inhibitory activity concentrations against $L$. monocytogenes.

( $)$ Organoleptic characteristics of foods were unaltered at $2 \%$ and $1 \%$ of Cinnamon bark oil.

( Essential oils from plant source can be employed for food preservation and to encourage 'green consumerism'.

Keywords: Agar well diffusion method, Antimicrobial, Essential oil, Minimum inhibitory concentration (MIC)

Food borne illnesses and food safety are the major public health issues still faced by people, inspite of being many improvements in slaughter hygiene, food production techniques and control programmes. This problem is aggravated by emergence of multi-drug resistance pathogens globally and is now recognized as global health challenge (Rai et al., 2017). The antibiotic resistance is due to overuse of antibiotics which can be attributed to over prescription and haphazard patient compliance.

L. monocytogenes is a Gram positive, facultative anaerobe, rod shaped and able to survive at wide range of temperatures from $-0.4^{\circ} \mathrm{C}$ to $45^{\circ} \mathrm{C}, \mathrm{pH}$ range from 4.0 to 9.6 with an optimum of $6-8$, at water activity $\left(a_{w}\right)$ levels of 0.90 (Valimaa et al., 2015). They have ability to form biofilms by adhering to different food contact surfaces like stainless steel, polystyrene at food processing facilities and persist for several months to years. $L$. monocytogenes biofilms can tolerate high concentrations of sanitizers, disinfectants and antimicrobials and can resist UV light, which results in contamination of food contact surface, in turn contaminating RTE foods, main

How to cite this article: Swetha, C.S., Kannan, P., Elango, A., Ronald B.S.M., Senthil Ku. T.M.A. and Sundaram, S. (2020). Evaluation of selected essential oils as biocontrol agents against Listeria monocytogenes. J. Anim. Res., 10(5): 803-809.

Source of Support: None; Conflict of Interest: None (c) 9 
cause of L. monocytogenes infection. As this organism has the ability to survive in low temperatures, both in aerobic and anaerobic conditions and in modified atmospheric packaging makes the food industry to take necessary actions and implement control measures along the food chain to prevent food borne listeriosis, which is a serious threat to public health (Valimaa et al., 2015).

The common preservative techniques followed by food industries will only improve organoleptic quality of food, but food safety was not completely assured. In addition, most of synthetic preservatives were restricted to use in food industries, negative perception of consumers towards these preservatives and increase in the interest of consumer towards 'green consumerism' had made the food industries to use plant based natural extracts as they are safe and ecofriendly (Prakash et al., 2018). From the past few years, research on essential oils and phytochemicals has shown that they can act as potential antimicrobials to prevent proliferation of pathogenic food bore microbes and further increases the shelf life of food products. Around 300 essential oils were considered as generally recognized as safe approval (GRAS) and can be used for flavouring or fragrance commercially and as biocontrol agent (Gray et al., 2018).

As there are only few reports of investigation on essential oils to use as biocontrol agents in food systems, the present study was designed to study the antimicrobial effect of essential oils viz., cinnamon bark oil, cinnamon leaf oil, clove bud oil and garlic oil against L. monocytogenes in foods.

\section{MATERIALS AND METHODS}

\section{Procurement of essential oils}

Four essential oils viz., Cinnamon bark oil, Cinnamon leaf oil, Clove oil and Garlic oil were obtained from M/s Kancor essential oils, Ernakulam, Kerala. All these essential oils were stored in amber colored bottles at $4^{\circ} \mathrm{C}$ for further use.

\section{Characterization of essential oils}

All the four essential oils were characterized by Gas Chromatography- Mass Spectrometry system $\left(789^{\circ} \mathrm{A}\right.$,
Agilent Technologies Inc., Santa Rosa, CA, USA) to know the chemical constituents present in them. This system is equipped with a HP-5 MS capillary column $(30 \mathrm{~m} \times 0.25$ $\mathrm{mm}, 0.25 \mathrm{~mm}$, Agilent Technologies Inc., Santa Rosa, CA, USA) and injected volume of each sample was $1 \mu \mathrm{L}$. Helium gas was used as carrier gas which has flow rate of 1 $\mathrm{mL} / \mathrm{min}$. The temperature of the injection port was $250^{\circ} \mathrm{C}$ and the temperatures programmed in the oven were: $50^{\circ} \mathrm{C}$ for $2 \mathrm{~min}$, then increased to $180^{\circ} \mathrm{C}$ at a rate of $5^{\circ} \mathrm{C} / \mathrm{min}$, followed by an increase to $270^{\circ} \mathrm{C}$ at a rate of $20^{\circ} \mathrm{C} / \mathrm{min}$ and maintenance at $270^{\circ} \mathrm{C}$ for $5 \mathrm{~min}$. The mass spectra used EI ion source temperature of $230^{\circ} \mathrm{C}$, ionization energy of $70 \mathrm{eV}$ and a mass scan range of 40-500 amu. The essential oil components were tentatively identified by comparing their mass spectra with the standards present in NIST library.

\section{Preparation of bacterial culture}

Four L. monocytogenes isolates obtained from milk, soil, beef, along with positive control (MTCC 1143) were used to determine antibacterial efficacy of essential oils. All these isolates were inoculated in Buffered Listeria Enrichment Broth (BLEB) and incubated at $37^{\circ} \mathrm{C}$ for 24 hrs. After incubation, the inoculum was centrifuged at 8000 rpm for 10 minutes and the supernatant was discarded. Then the sediment was washed twice with normal saline and centrifuged at $8000 \mathrm{rpm}$ for $10 \mathrm{~min}$. Supernatant was discarded and the cells were mixed with normal saline to get $0.5 \mathrm{McF}$ arland standard turbidity which indicates $1.5 \times 10^{8}$ cells $/ \mathrm{mL}$.

\section{Dilution of essential oils}

Essential oils were diluted a day prior to use with $1 \%$ of Tween 80 in requirement of concentrations of $2 \%, 1 \%$, $0.5 \%$ and $0.25 \%$. The diluted essential oils were stored at $4^{\circ} \mathrm{C}$ for further use.

Screening of essential oils for antibacterial activity against L. monocytogenes by Agar well diffusion method

The antibacterial activity of essential oils was tested by agar well diffusion method (Gupta et al., 2008). The standard L. monocytogenes isolate was inoculated in nutrient broth and incubated at $37^{\circ} \mathrm{C}$ for $24 \mathrm{hrs}$. The inoculum was 
adjusted to $10^{6} \mathrm{CFU} / \mathrm{ml}$ with McFarland standards. A 100 $\mu 1$ of test bacterial culture $\left(10^{6} \mathrm{CFU} / \mathrm{ml}\right)$ was spreaded on dried Mueller Hinton agar plates and left for 10 minutes. Holes were punched on the agar plates with $6 \mathrm{~mm}$ cork borer and $50 \mu \mathrm{l}$ each of four essential oils were poured in to different wells after sealing wells bottom with $1 \%$ agar. Sterile Tween 80 was kept as negative control. These plates were kept aside for one hour for proper diffusion of essential oils and incubated at $37^{\circ} \mathrm{C}$ for $24 \mathrm{hrs}$. The plates were prepared in duplicate. After incubation, the zones of inhibition were measured in $\mathrm{mm}$ and the sensitivity of each oil was compared with standards was given by Ponce et al., 2003 and Moreira et al., 2005: $<8$ mmNon sensitive; 9 to $14 \mathrm{~mm}$-Sensitive; 15 to $19 \mathrm{~mm}$ - Very sensitive; $>20 \mathrm{~mm}$-Extremely sensitive.

\section{Determination of minimum inhibitory concentration (MIC) by agar well diffusion method}

The Minimum Inhibitory Concentration (MIC) of Cinnamon bark oil, Cinnamon leaf oil, Clove bud oil, Garlic oil was also determined by agar well diffusion method (Gupta et al., 2008). The MIC was defined as the lowest concentration of essential oils at which no visible growth of bacteria was observed within $24 \mathrm{hrs}$ of incubation at $37^{\circ} \mathrm{C}$ (Thongson et al., 2004). Various concentrations of essential oils were prepared by two-fold dilution series to get concentrations of $2 \%, 1 \%, 0.5 \%$ and $0.25 \%$. A 50 $\mu l$ of various concentrations of essential oils were poured in to wells which were punched on Mueller Hinton agar plates spreaded with $10^{6} \mathrm{CFU} / \mathrm{ml}$ inoculum and incubated at $37^{\circ} \mathrm{C}$ for $24 \mathrm{hrs}$. The tests were done for twice. After incubation, zones of inhibitions were measured and the lowest concentration at which zone of inhibition was clear can be considered as MIC value of that essential oil.

\section{RESULTS AND DISCUSSION}

\section{Characterization of essential oils by GC-MS}

The chemical constituents present in Cinnamon bark oil, cinnamon leaf oil, clove bud oil and garlic oil were represented in Fig. 1 to 4 . The present study identified cinnamaldehyde $(74.76 \%)$ as the major chemical constituent in cinnamon bark oil and this is similar to findings of Mareim et al., 2020 and Jham et al., 2005 who reported $74.56 \%$ and $75 \%$ of cinnamaldehyde as major component in their studies. Sun et al., 2016 obtained a little high prevalence of cinnamaldehyde of $79.39 \%$ while Zhang et al. (2016) reported a very high percentage of cinnamaldehyde $(92.4 \%)$ in their studies respectively. Shan et al., 2007 in their study also identified $60-80 \%$ of cinnamaldehyde from the barks of Cinnamon zeylanicum which is almost similar to the present study. In contrary to this, other researchers identified $45.13 \%$ and $12.5 \%$ of cinnamaldehyde respectively (El-Baroty et al., 2010; Bayoub et al., 2010).

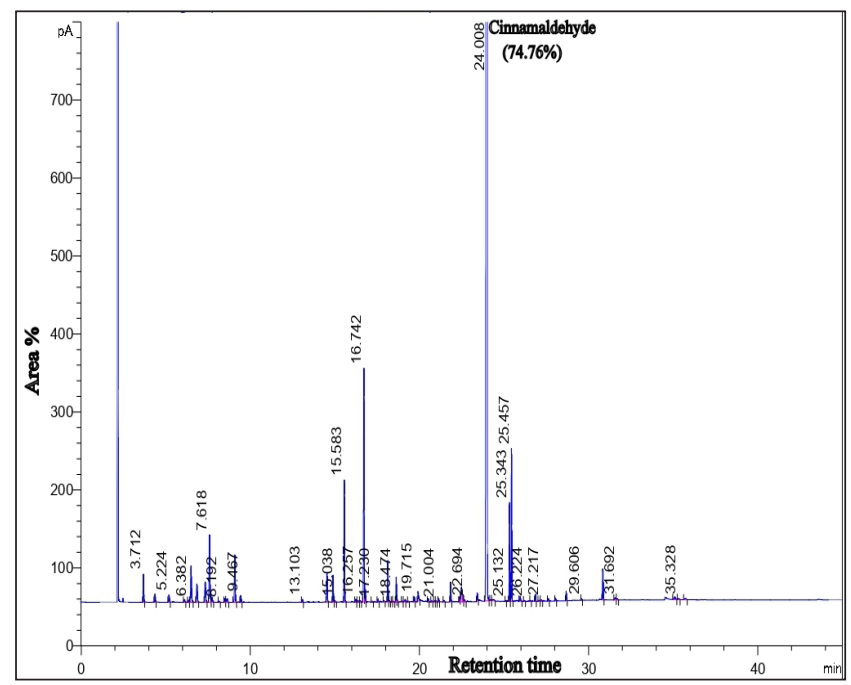

Fig. 1: GC-MS chromatogram of Cinnamon bark oil

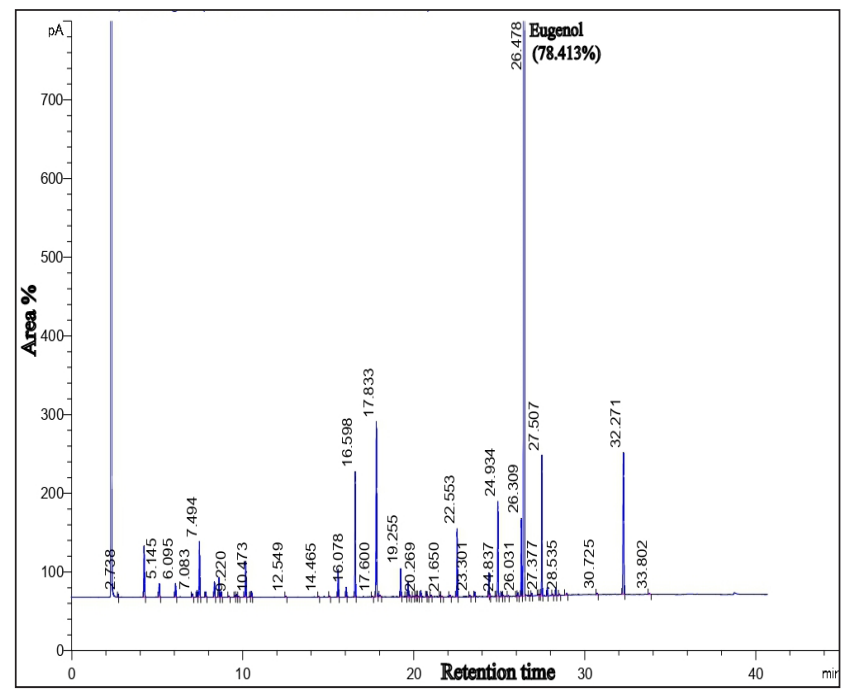

Fig. 2: GC-MS chromatogram of Cinnamon leaf oil 


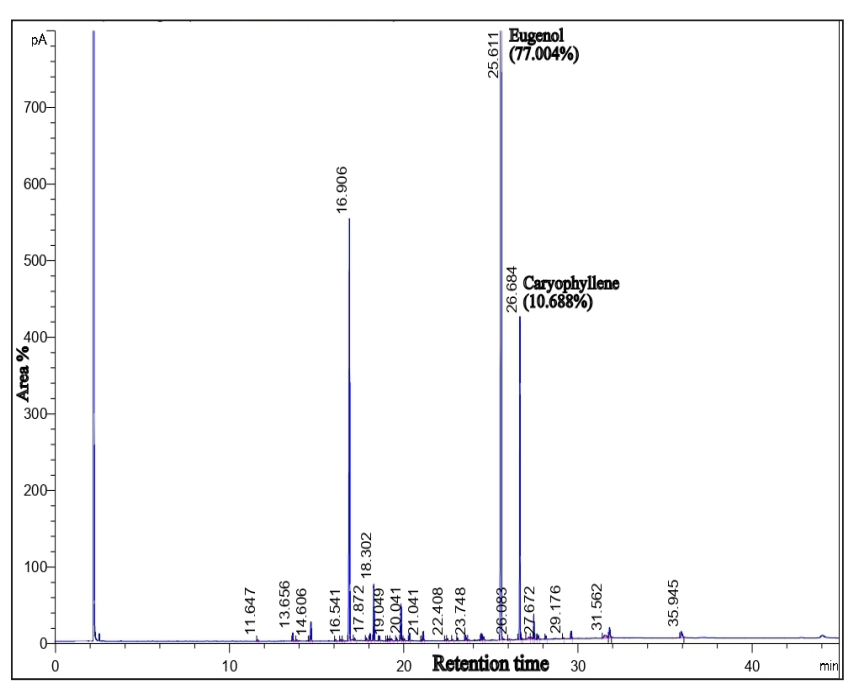

Fig. 3: GC-MS chromatogram of Clove bud oil

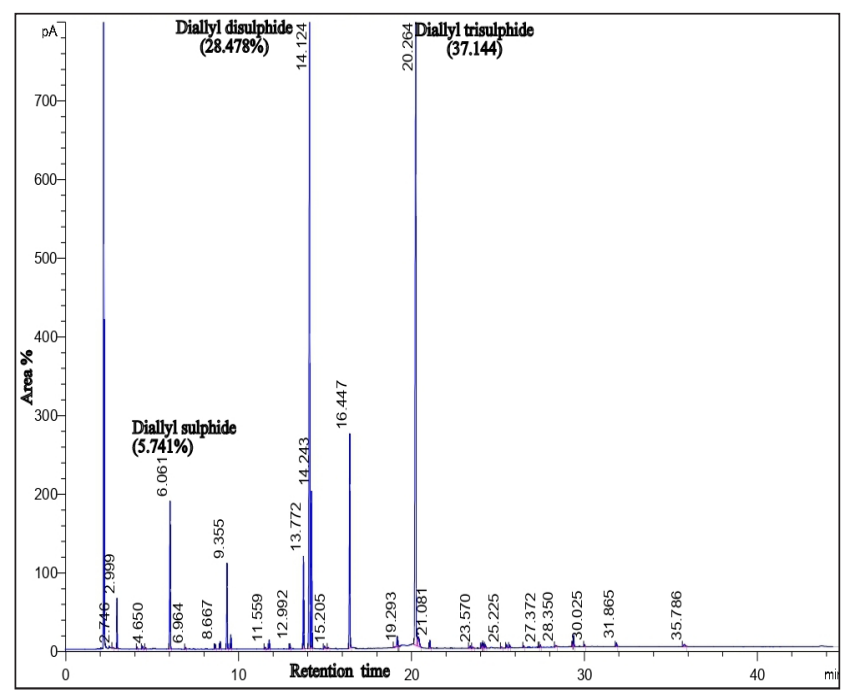

Fig. 4: GC-MS chromatogram of Garlic oil

Eugenol $(78.413 \%)$ is the main component found in cinnamon leaf oil in the present study which is similar to the findings of Bayoub et al., 2010 (76.91\%). Singh et al. (2007) also reported eugenol (85\%) as predominant component in cinnamon leaf oil which is slightly higher than the present study.

The main components identified in clove bud are Eugenol (77.004\%) and Caryophyllene (10.688\%) were similar to the Mith et al. (2014) who found same compounds with little high percentages - Eugenol $(84.75 \%)$ and beta caryophyllene (4.60\%). The studies of Cava et al. (2007) also determined cinnamaldehyde (67\%) and eugenol (4\%) as the important components in cinnamon bark oil while $4 \%$ cinnamaldehyde and $77 \%$ eugenol in cinnamon leaf oil; $86 \%$ eugenol and $<0.1 \%$ cinnamaldehyde in clove essential oils respectively.

On characterization of garlic oil in the present study, it was found that diallyl trisulphide (37.144\%), diallyl disulphide $(28.478 \%)$ and diallyl sulphide $(5.741 \%)$ were the main constituents. Mareim et al. (2020) recorded presence of diallyl trisulphide and diallyl disulphide in garlic oil with different percentages of 25.13 and 22.74. Razavi Rohani et al. (2011) also identified $27.33 \%$ of diallyl trisulphide, $24.67 \%$ of diallyl disulphide, $19.11 \%$ of methyl allyl trisulphide, $8.59 \%$ propenyldithiopropanoate, $2.18 \%$ dimethyl trisulfide, $2.13 \%$ diallyltetrasulfide, $1.49 \%$ of 3-vinyl-[4H]-1,2 dithin (3-VDT) and 1.25\% 2-vinyl[4H]-1,2 dithin (2-VDT). Similarly, El-Sayed et al., 2017 and Zhang et al., 2016, have also found similar compounds in garlic oil but with different concentrations.

These variations in the composition of essential oils from the present study to other studies may due to species, subspecies and variety of plants selected for preparation of essential oils, various agroclimatic conditions viz., climatic, seasonal and geographic of the regions, harvesting seasons (Mith et al., 2014), maturity stage and adaptive metabolism of plants, distillation conditions and the plant part analyzed (El-Baroty et al., 2010). The antimicrobial activity these essential oils also depends on the concentration of the phenolics compounds present in them, where at low concentrations, these phenolics compounds affects enzyme activity related to energy production and at high concentrations, causes protein precipitation (Prindle and Wright, 1997).

\section{Screening of essential oils for antibacterial activity against $L$. monocytogenes by agar well diffusion method}

All the four essential oils viz., cinnamon bark, cinnamon leaf, clove bud and garlic oils have shown antibacterial activity against L. monocytogenes. Among the four essential oils, cinnamon bark oil has shown with widest zone of inhibition $(27 \pm 0 \mathrm{~mm})$, followed by cinnamon leaf oil $(17 \pm 0 \mathrm{~mm})$, clove bud oil $(14 \pm 0 \mathrm{~mm})$ and garlic oil $(12 \pm 0 \mathrm{~mm})$.Similar to the present study, Ghabraie et al., 2015 in their agar diffusion assay studies, found that cinnamon bark oil and clove bud oil has shown highest 
inhibition diameters of approximately $27.8 \pm 0.6 \mathrm{~mm}$ and $14.8 \pm 0.3 \mathrm{~mm}$ among 32 essential oils used against L. monocytogenes. Babu et al., 2011 also observed that cinnamon oil $(25 \pm 0.06)$ has shown more zone of inhibition followed by clove $(21 \pm 0.08)$ and garlic $(17 \pm 0.18)$ oils in their studies. Hoque et al., 2008 also found $33 \mathrm{~mm}$ and $14 \mathrm{~mm}$ inhibition zones by testing the antimicrobial activity of cinnamon and clove essential oils against $L$. monocytogenes. In contrary to the present study, Mareim et al.(2020) recorded high zone of inhibition by garlic oil $(31 \pm 1.7 \mathrm{~mm})$ than cinnamon oil $(12.3 \pm 0.5)$ against L. monocytogenes. While, Smith and Palmer et al.(1998) have found $6.8 \mathrm{~mm}, 9.2 \mathrm{~mm}, 8.4 \mathrm{~mm}$ and $4 \mathrm{~mm}$ zones of inhibition showed by cinnamon bark, cinnamon leaf, clove and garlic oils against L. monocytogenes respectively. Bayoub et al. (2010) observed more zone of inhibition for clove oil $(25 \pm 10 \mathrm{~mm})$ than cinnamon oil $(22 \pm 0 \mathrm{~mm})$ against L. monocytogenes in their preliminary screening of essential oils. Similarly, in a study conducted by Shan et al., 2007, clove bud oil (13.7 $\mathrm{mm})$ showed more zone of inhibition than cinnamon oil $(8.9 \mathrm{~mm})$ against $L$. monocytogenes by agar well diffusion method.

\section{Determination of Minimum Inhibitory Concentration (MIC) by agar well diffusion method:}

The minimum inhibitory concentration (MIC) of the four essential oils viz., cinnamon bark oil, cinnamon leaf oil, clove bud oil and garlic oil were given in Table 1 .

Table 1: Minimum Inhibitory Concentrations (MIC) of essential oils against $L$. monocytogenes

\begin{tabular}{|c|c|c|c|c|}
\hline Test isolate & $\begin{array}{l}\text { Cinnamon } \\
\text { bark oil }\end{array}$ & $\begin{array}{l}\text { Cinnamon } \\
\text { leaf oil }\end{array}$ & $\begin{array}{l}\text { Clove } \\
\text { bud oil }\end{array}$ & $\begin{array}{l}\text { Garlic } \\
\text { oil }\end{array}$ \\
\hline Milk isolate & $1 \%$ & NA & NA & NA \\
\hline Soil isolate & $1 \%$ & NA & NA & NA \\
\hline Beef isolate & NA & NA & NA & NA \\
\hline $\begin{array}{l}\text { Positive control } \\
\text { (MTCC 1143) }\end{array}$ & $1 \%$ & NA & NA & NA \\
\hline
\end{tabular}

Among four essential oils, Cinnamon bark oil alone was found to be sensitive against $L$. monocytogenes at tested concentrations $(0.25 \%, 0.5 \%, 1 \%$ and $2 \%)$ with MIC of $1 \%$. These findings are similar to the studies of Gupta et al. (2008) who recorded 1.25\% MIC of cinnamon bark oil. In contrary, Mith et al. (2014) observed antilisteria activity of cinnamon oil against L.monocytogenes with a MIC of $0.125 \mu \mathrm{l} / \mathrm{ml}$; Bayoub et al.(2010) had MIC of $0.4 \mathrm{mg} / \mathrm{ml}$ for cinnamon oil against $L$. monocytogenes.

Though the cinnamon leaf oil, clove bud and garlic oils have shown antibacterial activity, but they didn't shown any zone of inhibitions at required concentrations $(2 \%$, $1 \%, 0.5 \%$ and $0.25 \%$ ) while determining MIC. In contrast to this, Wafaa et al. (2019) investigations showed the MIC of cinnamon leaf and bark oils against L. Monocytogenes was $0.5 \%(\mathrm{v} / \mathrm{v})$ and also reported that these oils can be used as potential antimicrobial agents to keep fresh produce safe from Listeria for human consumption.

In contrary to the clove bud oil findings in the present study, Menon and Garg (2001), Gupta et al. (2008), Barbosa et al. (2009) and Bayoub et al. (2010) have found the minimum inhibitory action of clove oil at a concentration of $1 \%, 5 \%$, $0.09 \%$ and $0.25 \mathrm{mg} / \mathrm{mL}$ against L. monocytogenes. Hoque et al. (2008) reported MIC values for cinnamon and clove essential oils were $1.25 \mathrm{mg} / \mathrm{ml}$ and $2.5 \mathrm{mg} / \mathrm{ml}$ respectively against $L$. monocytogenes.

Cava et al. (2007) also observed antimicrobial effect of cinnamon bark, cinnamon leaf and clove oils against $L$. monocytogenes in pasteurized milk stored at $7^{\circ} \mathrm{C}$ and $35^{\circ} \mathrm{C}$. They also observed strongest antimicrobial activity by cinnamon bark oil while cinnamon leaf and clove oils required higher concentrations for complete inhibition of growth of L. monocytogenes in pasteurized milk. They detected MIC value of $500 \mathrm{ppm}$ for cinnamon bark oil and $3000 \mathrm{ppm}$ of each for cinnamon leaf and clove oils respectively.

Similar to the present study, Indu et al. (2006) studies also found that garlic oil didn't show any inhibitory effect against growth of L. monocytogenes by agar well method. Kim et al. (2004) also found that garlic oil and its constituents have weak antibacterial activity with MIC value of 300 $\mu \mathrm{g} / \mathrm{mL}$ and Razavi et al. (2011) had found $100 \mu \mathrm{g} / \mathrm{mL}$ MIC values against L. monocytogenes. Kumar and Berwal (1998) had found $85 \%$ inhibition of L. monocytogenes at $10 \%$ garlic concentration and also determined MIC value at $8.8 \%$ respectively. Allicin or diallylthiosulphinic acid or diallyl disulphide was responsible for antimicrobial activity of garlic oil (Indu et al., 2006). Till now, only few works has been carried out on antibacterial activity of garlic oil due to rapid decomposition of the allicin, the major antibacterial compound in garlic, during the 
preparation of garlic essential oil (Razavi Rohani et al., 2011). The results may vary from one researcher to others due to selection of bacterial strains, volume of inoculum, incubation time and temperatures used in the experiments (Mith et al., 2014).

Our present study was mainly aimed to know the concentration of essential oils at which antibacterial activity was shown without change in the organoleptic characteristics of foods. In the present study, cinnamon bark oil only has shown activity against $L$. monocytogenes at $2 \%$ and $1 \%$ respectively while the remaining three essential oils didn't show any activity at required concentrations. The results obtained from the present study highlights the use of cinnamon bark oil in food industries as food preservative in foods against $L$. monocytogenes.

\section{CONCLUSION}

The results of the present study showed that all the four essential oils viz., cinnamon bark oil, cinnamon leaf oil, clove bud oil and garlic oils were sensitive against $L$. monocytogenes. Out of these four essential oils, cinnamon bark oil alone shown minimum inhibitory activity at $2 \%$ and $1 \%$ concentrations against $L$. monocytogenes without change in organoleptic characteristics of foods. The results of this study might be useful to introduce cinnamon bark oil as food preservative in food industries at low cost without altering nutrients and organoleptic characteristics. Many studies are required in future, to know antilisteria activity of these essential oils by changing the extraction procedure, increasing the concentrations of usage without compromising organoleptic characteristics of food in food industry to ensure food safety and public health and to minimize alter chemicals usage with plant based natural extracts for food preservation and to encourage 'green consumerism'.

\section{ACKNOWLEDGEMENTS}

The authors are grateful to TANUVAS, Government of India for providing funds for the present work.

\section{REFERENCES}

Barbosa, L.N., Vera Lucia, M.R., Fernandes, A.A.H., Ushimaru, Probst P.S. and Fernandes, A. 2009. Essential oils against foodborne pathogens and spoilage bacteria in minced meat. Foodborne Pathog. Dis., 6(6): 725-728.
Bayoub, K., Baibai, T., Mountassif, D.,Retmane, A and Abdelaziz Soukr. Antibacterial activities of the crude ethanol extracts of medicinal plants against Listeria monocytogenes and some other pathogenic strains. African J. Biotechnol.,9(27): 42514258.

Cava, R., Nowak, E., Taboada, A. and Marin-Iniesta, F. 2007. Antimicrobial activity of clove and cinnamon essential oils against Listeria monocytogenes in pasteurized milk. J. Food Prot., 70(12): 2757-2763.

El-Baroty, G.S., Abd El-Baky, H.H., Farag, R.S. and Saleh, M.A. 2010. Characterization of antioxidant and antimicrobial compounds of cinnamon and ginger essential oils. Afr. $J$. Biochem Res., 4(6): 167-174.

El-Sayed, H.S., Chizzola, R., Ramadan, A.A. and Edris, A.E. 2017. Chemical composition and antimicrobial activity of garlic essential oils evaluated in organic solvent, emulsifying, and self-micro emulsifying water based delivery systems. Food Chem., 221: 196-204.

Ghabraie, M., Vu, K.D., Tata, L., Salmieri, S. and Lacroix, M. 2015. Antimicrobial effect of essential oils in combinations against five bacteria and their effect on sensorial quality of ground meat. LWT - Food Science and Tech., doi: 10.1016/j. lwt.2015.10.055.

Gray, J.A., Chandry, P.S., Kaur, M., Kocharunchitt, C., Bowman, J.P. and Fox, E.M. 2018. Novel biocontrol methods for Listeria monocytogenes biofilms in food production facilities. Front. Microbiol., 9: 605.

Gupta Charu, Amar P. Garg, Ramesh C. Uniyal and Archana Kumari. 2008. Antimicrobial activity of some herbal oils against common food-borne pathogens. Afri. J. Micronbiol. Res., 2: 258-261.

Hoque Md. Mahfuzul, Barih, M.L., Vijay K. Jun and Kawamoto, S. 2008. Antimicrobial activity of cloves and cinnamon extracts against food borne pathogens and spoilage bacteria and inactivation of Listeria monocytogenes in Ground Chicken meat with their Essential oils. Rep. Nat'l. Food Res. Inst., 72: 9-21.

Indu, M.N., Hatha, A.A.M., Abirosh, C., Harsha, U. and Vivekanandan, G. 2006. Antimicrobial activity of some of the south-Indian spices against serotypes of Escherichia coli, Salmonella, Listeria monocytogenes and Aeromonas hydrophila. Braz. J. Microbiol., 37: 153-158.

Jagadeesh Babu, A., Rupa Sundari A., Indumathi, J., Srujan, R.V.N. and Sravanthi, M. 2011. Study on the Antimicrobial activity and Minimum Inhibitory Concentration of Essential Oils of Spices. Vet. World, 4(7): 311-316.

Jham, G.N., Onkar, D.D., Carolina, M.J. and Vânia, M.M.V. 2005. Identification of the major fungitoxic component of cinnamon bark oil. Fitopatol. Bras., 30(4): 404-407. 
Kim, S. and Fung, D.Y. 2004. Antibacterial effect of watersoluble arrowroot (Puerariae radix) tea extracts on foodborne pathogens in ground beef and mushroom soup. J. Food Prot., 67(9): 1953-1956.

Kumar, M. and Berwal, J.S. 1998. Sensitivity of food pathogens to garlic (Allium sativum). J. Appl. Microbiol., 84: 213-215.

MariemSomrani, Inglés, M.C., Debbabi, H., Abidi, F. and Alfredo Palop. 2020. Garlic, onion, and cinnamon essential oil anti-biofilms' effect against Listeria monocytogenes. Foods, 9: 567.

Menon, V. and S. R. Garg. 2001. Inhibitory effect of clove oil on Listeria monocytogenes in meat and cheese. Food Microbiol., 18: $647-650$.

Mith H., Dure' R., Delcenserie V., Zhiri A., Daube G. and Clinquart A. 2014. Antimicrobial activities of commercial essential oils and their components against food-borne pathogens and food spoilage bacteria. Food Sci. Nutrion, 2: 403-41.

Moreira, M.R., Ponce, A.G., de Valle, C.E. and Roura, S.I. 2005. Inhibitory parameters of essential oils to reduce a foodborne pathogen. Lebensmittel-Wissenschaft und -TechnologieLWT., 38: 565-570.

Ponce, A.G., Fritz, R., del Valle, C. And Roura, S.I. 2003. Antimicrobial activity of essential oils on the native microflora of organic Swiss chard. Lebensmittel-Wissenschaft und-Technologie-LWT., 36: 679-684.

Prakash, B., AnupamKujur, Amrita Yadav, Akshay Kumar, PremPratap Singh. 2008. Nanoencapsulation: An efficient technology to boost the antimicrobial potential of plant essential oils in food system. Food Control, 89: 1-11.

Prindle, R.F., Wright, E.S. 1997. Phenolic compounds. In S. S. Block (Ed.). Disinfection, sterilization and preservation. Philadelfia: Lea \& Febiger.

Rai, M., Priti Paralikar, Priti Jogee, Gauravi Agarkar, Avinash P. Ingle, Marcos Derita and Susana Zacchino. 2017. Synergistic antimicrobial potential of essential oils in combination with nanoparticles: Emerging trends and future perspectives. Int. J. Pharma., http://dx.doi.org/10.1016/j.ijpharm.2017.01.013.
Razavi Rohani S.M, Mehran, M., Mehdizadeh, T., SiavashSaeiDehkordi, S. and Mansel W. Griffiths. 2011. The effect of nisin and garlic (Allium sativum L.) essential oil separately and in combination on the growth of Listeria monocytogenes. LWT - Food Sci. Technol.,44: 2260-2265.

Shan, B., Cai, Y., Brooks, J.D. and Corke, H. 2007. The in vitro antibacterial activity of dietary spice and medicinal herb extracts. Int. J. Food Microbiol.,117: 112-119.

Singh, G., Maurya, S., De Lampasona, M.P., Catalan, C.A.N. 2007. A comparison of chemical, antioxidant and antimicrobial studies of cinnamon leaf and bark volatile oils, oleoresins and their constituents. Food Chem. Toxicol., 45: 1650-1661.

Smith-Palmer, A., Stewart, J. and Fyfe, L. 1998. Antimicrobial properties of plant essential oils and essences against five important food-borne pathogens. Lett. Food Microbiol., 26: $118-122$.

Sun, L., Zong, S.B., Li, J.C., Lv, Y.Z., Liu, L.N., Wang, Z.Z., Zhou, J., Cao, L., Kou, J.P. and Xiao, W. 2016. The essential oil from the twigs of Cinnamomum cassia Presl alleviates pain and inflammation in mice. J. Ethnopharmacol., 194: 904-912.

Thongson, C., Davidson, P.M., Mahakarnchanakul, W., Weiss, J. 2004. Antimicrobial activity of ultrasound-assisted solventextracted spices. Lett. Appl. Microbiol., 39(5): 401-406.

Valimaa, A.L., AnuTilsala-Timisjarvi and Elina Virtanen. 2015. Rapid detection and identification methods for Listeria monocytogenes in the food chain - A review. Food Control, 55: 103-114.

Zhang, Y., Liu, X., Wang, Y., Jiang, P. and Quek, S. 2016. Antibacterial activity and mechanism of cinnamon essential oil against Escherichia coli and Staphylococcus aureus. Food Control, 59: 282-289. 
